\title{
Cartaphilus
}

Revista de investigación y crítica estética

\section{LA POSIBILIDAD CÓMICA \\ EN LAS ESTÉTICAS DE LA NEGATIVIDAD}

THE COMIC POSSIBILITY

IN THE AESTHETICS OF NEGATIVITY

\section{XABIER ORTIZ DE URBINA ARANDIGOIEN}

UNIVERSITAT AUTÒNOMA DE BARCELONA

Resumen: El presente artículo pretende ofrecer una actualización acerca de la relación entre la experiencia humorística y las llamadas estéticas negativas. Desde que Aristóteles definiera la comedia como la imitación de los rasgos ridículos del ser humano, los cuales pertenecen a la categoría de lo feo, lo cómico y lo humorístico han sido muchas veces enumerados dentro de las categorías estéticas de la negatividad frente a las estéticas relacionadas con la belleza. En contraposición, se encuentran teorías como las de Theodor Lipps, quien asegura que el valor de la comicidad no es un valor estético, sino que responde a una forma de juicio distinta, como también adelantó el propio Kant. Se pretende así plantear una discusión a partir de estos dos postulados y ofrecer una posible salida.

Palabras clave: Humor, comedia, estéticas negativas, fealdad.

\begin{abstract}
This article aims to offer an update on the relationship between the humorous experience and negative aesthetics. Since Aristotle defined comedy as the imitation of the ridiculous traits of the human being, as a part of the ugly aesthetics, the comic and the humorous have often been listed within the aesthetic categories of negativity in front of the aesthetics related to beauty. In contrast, there are theories like those of Theodor Lipps, who assures that the value of humor is not an aesthetic value, but responds to a different form of judgment, as Kant also advanced. The aim is to propose a discussion based on these two postulates and offer a possible solution.
\end{abstract}

Key words: Humor, comedy, negative aesthetics, the ugly 


\section{INTRODUCCIÓN}

Desde que Aristóteles definiera el género cómico como "una imitación de los hombres peor de lo que son; peor, en efecto, no en cuanto a algunas y cada tipo de faltas, sino sólo referente a una clase particular, lo ridículo, que es una especie de lo feo" (Aristóteles, 1999, p.12), a lo que añade que "lo ridículo puede ser definido acaso como un error o deformidad que no produce dolor ni daño a otros" (Aristóteles, 1999, p.12), puede considerarse oportuno un acercamiento a las Ilamadas estéticas negativas desde la óptica de lo cómico. Sin embargo, la aparente sencillez con la que el pensador griego define la comedia contrasta con el rompecabezas que ha supuesto para otros filósofos posteriores ofrecer unas mínimas certezas sobre el asunto. Dicha dificultad tiene que ver con que otros conceptos más problemáticos como la comicidad o la propia cuestión del humor han pasado a formar parte de la ecuación. En su definición de la comedia Aristóteles parece tener muy claro a lo que se está refiriendo al apuntar a esa parte concreta de lo feo que es lo ridículo, al igual que parece dar a entender que aquello que no produce dolor ni daño a otros consiste en una característica homologable universalmente. Tal vez, siguiendo el argumento de El nombre de la rosa, Aristóteles dedicara ese segundo tomo de su Poética a abordar la complejidad que el asunto indudablemente tiene.

El segundo motivo para este acercamiento tiene que ver con el siguiente punto de (des)encuentro: mientras Aristóteles basaba su idea de comedia en la imitación de los aspectos ridículos del ser humano, los cuales se encontraban dentro de la categoría de lo feo, Theodor W. Adorno abogó en su teoría estética por un arte dedicado a esa misma categoría de lo feo, pero con la particularidad de que cualquier acercamiento al ámbito del humor constituía la mayor de las abyecciones. Adorno lo argumentó de la siguiente manera:

El arte tiene que adoptar la causa de todo lo proscrito por feo, pero no para integrarlo, mitigarlo o reconciliarlo con su existencia mediante el humor (que es más repugnante que todo lo repugnante), sino para denunciar en lo feo al mundo que lo crea y reproduce a su imagen y semejanza; la posibilidad de lo afirmativo pervive incluso ahí en tanto que conformidad con la humillación y se convierte fácilmente en simpatía con los humillados. (Adorno, 1971, p.96)

Mucho antes de que lo hiciera Adorno, otras voces de peso también se manifestaron en contra de la inclusión del humor en ciertos ámbitos de la vida. Thomas Hobbes, por su parte, señaló que "mucha risa ante los defectos de otros es un signo de pusilanimidad. Pues una de las labores propias de las grandes mentes es ayudar y liberar a otros del desdén, y compararse a sí mismos solamente con los más capaces" (Hobbes, 1980, p.163). En la misma línea se expresó Baudelaire, quien se refirió a la risa poco menos que de diabólica, característica que la convertía, según el autor, en profundamente humana: 
¿Qué hay de regocijante en el espectáculo de un hombre que cae en el hielo o en el pavimento, que tropieza en el borde de una acera? (...) Si queremos ahondar en esta situación encontraremos en el fondo del pensamiento del que ríe cierto orgullo inconsciente. Es el punto de partida: yo no me caigo; yo, camino derecho; yo, mi pie es firme y seguro. No sería yo quien cometería la tontería de no ver una acera cortada o un adoquín que cierra el paso. (Baudelaire, 1988, p.24)

Apuntando al ámbito de la creación literaria fue Ortega quien arremetió duramente contra la novela picaresca española, argumentando que "la novela picaresca es, en su forma extrema, una literatura corrosiva (...) No tiene independencia estética; necesita de la realidad fuera de ella, de la cual es ella crítica, de la que vive como carcoma de la madera" (Ortega, 1963, p.121-124).

Lo problemático de algunas de estas críticas es su falta de concreción, de manera que contribuyen con una cierta confusión en la que no se sabe si aquello que se critica pertenece al ámbito de lo estético, de lo moral o de lo político. En este sentido, Gómez Haro, en su exhaustivo estudio sobre el humor, apunta cómo a partir del siglo XVIII la filosofía estética trasciende lo bello por elevación -lo sublime- y por degradación, "-cosa de la que se ocupará el post-hegelianismo-, prestando atención a lo feo, lo cómico, lo humorístico, lo grotesco, lo nauseabundo, o lo terrible, entendidos tales conceptos como diferentes grados de la belleza en su pura negatividad" (Gómez Haro, 2013, p.10). Sin embargo, Gómez Haro reconoce que "la crítica siempre prefirió hablar antes de ironía -un concepto de clara raigambre retórica-, que de humor, un término tan etéreo y tan esquivo que apenas si se sabe definir con claridad (...) Es por eso que para Bergson, al igual que pensaba Freud, lo cómico no podía ser más que un momento, algo que realmente no puede llegar a autonomizarse completamente en un espacio artístico adecuado" (Gómez Haro, 2013, pp.11-43). Pese a una llamativa coincidencia en el tiempo de los estudios más notables hasta la fecha -Baudelaire, Lipps, Freud, Bergson- durante el periodo de cambio del siglo XIX al XX, debe insistirse que en todo el siglo XX la cuestión del humor y lo cómico ha sido ignorada por los estudiosos del arte, ya que su carácter paradójico -o parasitario, siguiendo a Ortega- ha dificultado su inclusión en cualquier categoría epistemológica.

De cara a situar la propuesta crítica del artículo, debe matizarse que Adorno, en su defensa de la estética negra, indultó aquellos acercamientos al terreno humorístico en los que el propio humor ejerce de cortafuegos frente al mayor de los peligros: que el público ría:

En conformidad con la tendencia del arte moderno a tematizar sus propias categorías mediante la autorreflexión, obras como Esperando a Godot o Fin de parti$d a$ (en la escena en que los protagonistas deciden reír) son lo cómico convertido en trágico, a más que son cómicas; esa risa sobre el escenario hace que el espectador pierda las ganas de reír. (Adorno, 1971, p.517). 
Es posible observar que la denuncia de Adorno se dirige fundamentalmente al efecto balsámico de la risa que los espectáculos cómicos producen en el público, ya que el filósofo creía firmemente que las obras oscuras de Beckett o Kafka "ayudaron al público a través de su negatividad a pensar correctamente sobre la injusticia, la alineación y la inhumanidad"(Vilar, 2018, pp.15-25). Por tanto, la crítica de Adorno al humor es, esencialmente, de índole política, mientras que las críticas de Hobbes o Baudelaire parecen apuntar más al ámbito de la moral. Sin embargo, este artículo pretende ocuparse de la relación entre las llamadas negatividades estéticas y el humor, partiendo de que en ocasiones lo humorístico o lo cómico se enumera, no sin cierta pereza, junto con otras categorías estéticas como lo grotesco, lo feo o lo asqueroso. Como se ha visto, esto se problematiza cuando algunas corrientes literarias que se aproximan al ámbito humorístico, como la novela picaresca, son criticadas por su falta de independencia estética. Estas observaciones de Ortega se pueden emparentar con la teoría sobre el humor y lo cómico de Theodor Lipps, quien afirma rotundamente que "el valor de la comicidad no es un valor estético" (Lipps, 2015, p.290), ya que "el valor estético es un valor intrínseco" (Lipps, 2015, p.270), es decir, "un valor del cual nos percatamos en la medida en la que tenemos presente únicamente ese objeto tal cual es o tal cual se nos presenta y permitimos que obre su efecto sobre nosotros" (Lipps, 2015, p.270).

Es evidente que todos estos cruces de ideas necesitan de un cierto orden, de manera que, con la voluntad de contribuir con él, se plantean dos objetivos fundamentales para este escrito: en primer lugar, situar en el eje sujeto-objeto una serie de conceptos que forman parte de una demostrable confusión generalizada acerca de la experiencia humorística y su relación con la estética. En segundo lugar, se propone una posible relación entre dicha experiencia humorística y las llamadas estéticas negativas.

\section{LA EXPERIENCIA HUMORÍSTICA}

La definición de la comedia que ofrece Aristóteles hace hincapié en la naturaleza mimética -y poiética- de dicho género, en la cual se entiende que lo cómico se encuentra concretamente en un subgénero dentro de la categoría estética de lo feo al que se refiere como lo ridículo. Es decir, se trata de una explicación que se fija estrictamente en el objeto y deja de lado el ámbito del sujeto que contempla esa práctica mimética. Sin embargo, Aristóteles en ningún momento habla de que dicha (re)presentación de los aspectos ridículos del hombre tenga que provocar necesariamente la risa del espectador. En su prudencia reside, pues, su virtud, ya que dicha definición también puede interpretarse a la manera opuesta; es decir, cuando se refiere a lo ridículo como un error o deformidad menor que no produce daño a otros, dentro de esos otros puede estar incluido el propio espectador, de forma que será este mismo a través de su sentido 
de lo ridículo y su ausencia de dolor quien otorgue al objeto la categoría de comedia. Esta lectura nos pone en la pista de la tesis que aquí se pretende defender, que consiste en invertir la dirección objeto-sujeto y trazar una suerte de giro copernicano que se aplique a la experiencia humorística.

Las aproximación de Kant a la cuestión del humor, abordada de forma escueta en su tercera crítica, ya transita en esta dirección, al referirse a esta facultad como "el talento de poder ponerse voluntariamente en una cierta disposición del espíritu, en la cual todas las cosas son juzgadas de una manera totalmente distinta de la ordinaria, y sin embargo, conforme con ciertos principios de la razón" (Kant, 1997, p.298). En los mismos términos define el humor el neurocientífico Scott Weems al afirmar también que se trata de una facultad, más concretamente de "un rasgo evolutivo tan importante como la inteligencia, porque sin él no podríamos hacer frente al mundo complejo que hemos creado" (Weems, 2015, p.221). Se trata, pues, de considerar la facultad humorística como una característica propiamente humana, es decir, perteneciente al ámbito del sujeto y no del objeto:

Aunque por producto de humor hoy se entienda el espectáculo destinado a ser consumido para divertirse en compañía, hablando con rigor sería el espectáculo cómico el que tiene ese destino (...) El humor es previo a toda especie literaria o producto estético de cualquier índole. (Gómez Haro, 2013, p.23).

Weems determina que "el humor por naturaleza viene caracterizado por una confrontación, a veces cognitiva, a veces emocional” (Weems, 2015, p.47), de manera que el sujeto podrá incluso experimentar el humor sin salir de sí mismo, a través, por ejemplo, de revivir acontecimientos biográficos del pasado que produzcan dicho conflicto cognitivo o emocional en el momento de ser rememorados, en cuyo caso, dichos acontecimientos rememorados podrán calificarse de humorísticos sin la necesidad de que en el momento pretérito en que fueron vividos fueran así considerados.

Antes de continuar con la argumentación se vuelve necesario un consenso -a pesar de que parezca una cuestión obvia- acerca de que el espectáculo de comedia o cualquier objeto que se considere cómico tiene como propósito fundamental activar en el espectador su facultad para el humor. Dicho de otra manera, se propone el objeto cómico sumir al espectador en una experiencia humorística, es decir, en una experiencia placentera cuya respuesta fisiológica es la risa. Por lo tanto, debe ser asumida la imposibilidad de referirse a los objetos cómicos en términos absolutos, sean estos objetos artísticos o no, ya que es el sujeto quien otorga esta facultad al objeto. Esto así, lo prudente sería hablar en términos de posibilidades cómicas o potencial cómico. Tal y como explica T. Lipps con notable sesgo kantiano, el ser humano, gracias a su sentido del humor, es capaz de encontrar en su entorno objetos que pasan a ser cómicos: 
Yo "tengo" humor cuando estoy en ese estado de ánimo o cuando me entrego a esa forma de contemplación. Aquí yo mismo soy el encumbrado, el que se impone, el portador de lo sensato o moral. En mi calidad de encumbrado a la luz de esto sublime es que contemplo el mundo. Encuentro en ello cosas cómicas y me adentro de manera contemplativa en la comicidad. Pero finalmente me recupero a mí mismo, o a lo sublime que hay en mí, de manera más elevada, reforzada, intensificada. De esta manera termina aquí el proceso humorístico. (Lipps, 2015, p.323)

La descripción del proceso humorístico aportada por Lipps suma a la ecuación el concepto de comicidad, que viene a significar -y sustantivar- las cualidades de cómico o humorístico -sinónimos éstos- que se le atribuyen al objeto. El meollo de la discusión viene dado a partir de la confrontación entre quienes han tratado lo cómico como una categoría estética contigua a otras de las llamadas estéticas negativas -como lo siniestro o lo grotesco- y otra corriente encarnada definitivamente por Theodor Lipps, quien afirma que el valor de la comicidad no puede ser considerado como un valor estético. Siguiendo a Lipps, por tanto, lo cómico no puede definirse como una categoría estética, ni negativa ni positiva. Los máximos contribuyentes a la confusión existente en este ámbito han sido aquellos que, considerando lo cómico una categoría estética, han tratado de definir sus procesos internos en términos absolutos. Kierkegaard puede ser ejemplo de ello:

Lo cómico siempre se basa sobre la contradicción. Si un hombre intenta establecerse como dueño de una taberna y falla esto no es cómico. Sin embargo, si una muchacha intenta obtener un permiso para establecerse como prostituta y falla, que ocurre a veces, esto es cómico: muy cómico, debido a que contiene muchas contradicciones. (Kierkegaard, 2006, p.2226)

Este tipo de afirmaciones absolutistas únicamente se legitiman desde una posición ciertamente impotente, que consiste en separar lo cómico de la experiencia humorística, es decir, a partir de la defensa de una comicidad, un género cómico o una estética cómica que trabaje independientemente del humor y la risa. Dicha impotencia se hace manifiesta cuando entre estos postulados no se generan consensos acerca del tipo de emoción que dicha estrategia estética persigue: mientras se asume sin mayor problema que lo trágico busca la empatía o la compasión a través de sus personajes, o que algunas estéticas negativas como lo grotesco o lo siniestro buscan un cierto sentimiento de repulsión o desasosiego en el espectador, a propósito de lo cómico se acaba cayendo en simplezas o, lo que es peor, en un cul-de-sac:

Si bien lo cómico puede ser humorístico, no todo lo cómico se reduce al humor, ya que lo humorístico pretende causar la risa mientras que lo cómico se centra en la contradicción que la mayor de las veces es risible, más no siempre. (Cava- 
Ilazzi, 2016, p.2)

Si asumimos, de la mano de Lipps, que lo cómico debe quedar fuera de las categorías estéticas, se vuelve necesario identificar el lugar exacto donde se aloja la comicidad en relación al objeto, para finalmente pasar a la propuesta de relación entre la experiencia humorística en su conjunto y las estéticas de la negatividad que podemos asumir como tales. Como se ha observado, si es posible concebir lo grotesco o lo siniestro dentro de las estéticas negativas es debido a que cada una de ellas persigue, generalmente, provocar en el espectador una emoción unívoca a través de unas propiedades estéticas visibles o detectables en términos sensibles en el propio objeto. Frente a esa emoción unívoca u homogénea, la comicidad está supeditada, como bien indica Weems, a una confrontación cognitiva o emocional.

\section{EL HUMOR FRENTE A LAS ESTÉTICAS NEGATIVAS}

Gómez Haro apunta que "hay pocos grotescos lo suficientemente divertidos como para alejar de ellos cualquier sombra de terror, y pocos grotescos tan terribles como para excluir en ello toda idea de broma"(Gómez Haro, 2013, p.51), por lo que la tarea esencial consiste en determinar de qué depende que la balanza se decante hacia uno u otro lado. Si observamos una de las secuencias de la controvertida película-documental En el sótano (Im keller, Ulrich Seidl, 2014), donde, en el contexto de una pareja que mantiene una relación sadomasoquista, la mujer cuelga varios objetos de peso de los testículos del hombre mientras éste gime de placer y dolor, nos encontramos ante dos posibles tipos de juicio que requieren, a su vez y siguiendo a Kant, de dos tipos de disposiciones bien distintas. La simetría ahogadora del encuadre, una gélida iluminación y lo extremo de la acción perpetrada por los personajes componen una escena calificable de grotesca, la cual nos conduce a una experiencia estética desgarradora y desasosegante. Sin embargo, una disposición distinta frente al mismo objeto puede derivar en una momentánea suspensión del sentido estético para pasar a una disposición humorística, es decir, pasar de una cierta homogeneidad emocional a una situación de confrontación cognitiva en la que los hechos no se juzgan por sus propiedades estéticas sino por la acción mostrada en relación al ser humano en general. De manera que la comicidad de un objeto artístico tiene que ver con su capacidad de suspender el juicio estético a favor de un juicio absoluto, en el que se confronta el contenido del objeto con la concepción general del ser humano. 


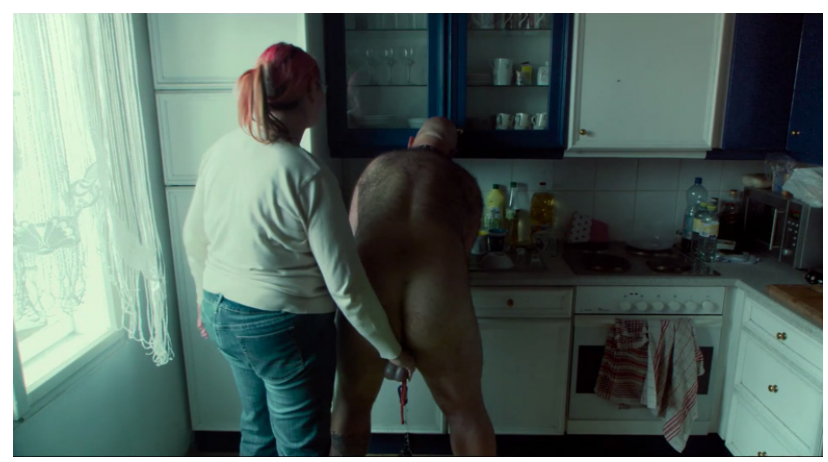

Imagen 1

En el sótano (Im Keller). Ulrich Seidl, 2014

El sentido del humor tiende a descontextualizar, de ahí la tendencia de lo pretendidamente cómico a la imitación y la parodia, a la que Lipps se refiere en los términos arriba apuntados:

Ahora, en cierta forma se convierte en objeto de un juicio absoluto, es decir, en lugar de en relación con su portador, penetra la conciencia en su relación con el ser humano en general. Se le mide en relación con lo que se espera del ser humano en general. $Y$ en este contexto se presenta como pequeñez, y surte el efecto correspondiente. Surte un efecto cómico. (Lipps, 2015, p.74)

Otorgar la condición de cómico a un objeto consiste en reconocer a dicho objeto su participación en el conflicto cognitivo o emocional que supone la experiencia humorística. Dicha experiencia, por tanto, depende de que se mantenga la tensión del conflicto cognitivo, de que no decaiga hacia un sentimiento unívoco. El elemento que juega a favor de dicha tensión es lo que Bergson llama artificios:

Lo cómico se dirige a la inteligencia pura: la risa es incompatible con la emoción. Señaladme un defecto, todo lo leve que queráis; si me lo presentáis de modo que conmueva mi simpatía, mi temor o mi piedad, todo habrá terminado, no podré seguir riéndome. Escoged, por el contrario, un vicio grave y hasta odiado por todos; si lográis con artificios que me deje insensible, acabaréis por hacerlo cómico. No quiero decir que entonces será cómico el vicio, sino que desde entonces podrá llegar a serlo. Es necesario que no me conmueva. (Bergson, 1985, p.50)

Los artificios a los que se refiere Bergson, así como sus efectos inhibidores a favor de la tensión cómica se mueven, en el contexto de los objetos artísticos, en el eje de la poética, la estética y la ética. A modo de ejemplo sirve una comparación entre Las Hurdes (Tierra sin pan) (Terre Sans Pain, Luís Buñuel, 
1936) ${ }^{1}$ y La parada de los monstruos (Freaks, Todd Browning, 1932). Si bien en ambas películas se muestra la fealdad de personajes con malformaciones -con los que Buñuel en una de las secuencias finales se ensaña calificándolos de "cretinos" a través de su voz en off- debe resaltarse una diferencia poética determinante que condiciona por completo su potencial cómico: la fuerza poiética del documental de Buñuel es infinitamente inferior a la poiésis propia de la ficción de la que goza Freaks, de manera que el artificio inhibidor de la ficción cinematográfica se impone a la poiésis del documental a la hora de mantener la tensión cómica, dado que en el documental los hechos son percibidos como reales.

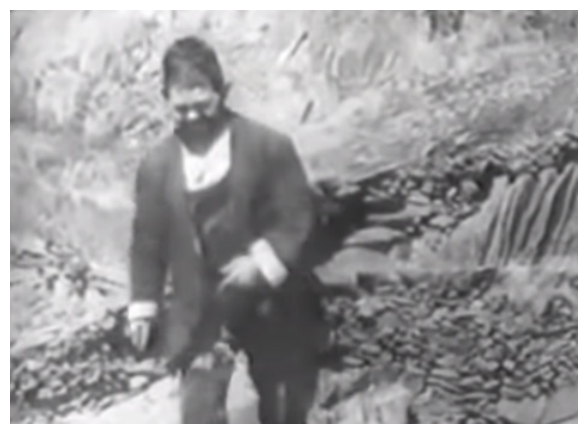

Imagen 2

Las Hurdes (Tierra sin pan) (Terre Sans Pain),

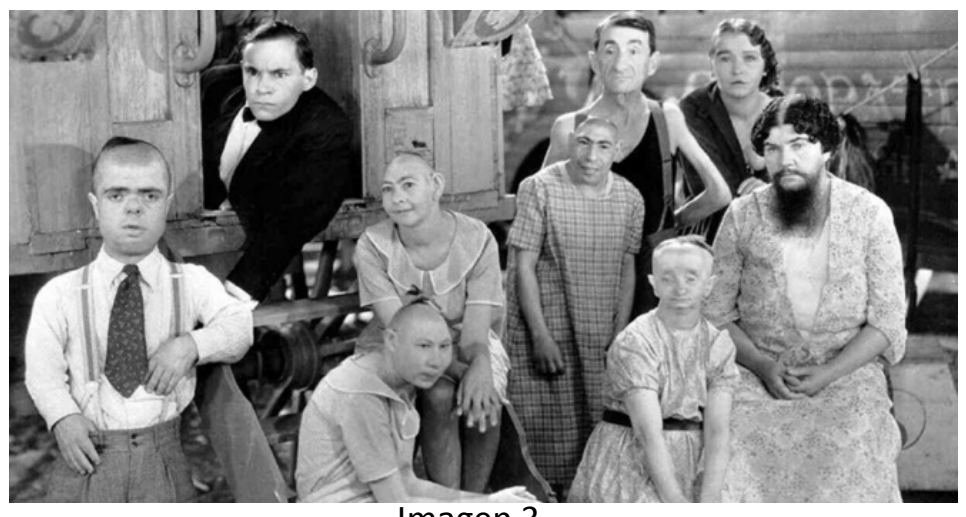

Imagen 3

La parada de los monstruos (Freaks),

Todd Browning, 1932

El segundo elemento fundamental que contribuye con mantener al sujeto en disposición humorística tiene que ver con esa unión wittgensteiniana -pero también kantiana- entre ética y estética.

En la poiésis, o creación, resuena, pues, la praxis, o el modo de conducir el ethos a través de ésta. Pero lo hace a través de una meditación (indirecta, analógica) de las Ideas que pueden orientar dicha acción. Ideas relativas a nuestra propia condición, y a su propensión a conductas inhumanas. (Trías, 2000, p.172)

\footnotetext{
${ }^{1}$ Nos acogemos a la versión francesa con comentario en off estrenada en 1936
} 
La idea de Kant del resonar ético de lo artístico también se puede encontrar en Hegel cuando éste se refiere al humorismo, al señalar que "en el humor es la persona misma del artista la que se presenta en escena toda entera (...) de suerte que se trata, esencialmente del valor espiritual de esa personalidad" (Hegel, 2003, p.272). En este sentido, la tensión cómica se mantendrá siempre y cuando se de una cierta asepsia o higiene ética. Dicho a la inversa, la experiencia humorística se verá frustrada cuando la resonancia ética del objeto-que puede ser revelada por propiedades estéticas o extra-estéticas- produzca una distensión del conflicto cognitivo hacia emociones más homogéneas o unívocas.

Se puede decir que la comicidad, recuperando el carácter parasitario acuñado por Ortega, habita de forma potencial en algunas de las categorías estéticas negativas pero, parafraseando a Lipps, no forma parte de ellas de manera intrínseca. Así, el humor permanece a merced de que se den unos condicionantes poéticos, estéticos y éticos concretos en el objeto artístico, así como de que las actitudes humanas que se muestran tengan potencial para incorporarse a un conflicto cognitivo o emocional en relación a una concepción absoluta del ser humano, ya que, como dicta Bergson al comienzo de su estudio, "fuera de lo que es propiamente humano, no hay nada cómico. Un paisaje podrá ser bello, sublime, insignificante o feo, pero nunca ridículo" (Bergson, 1985, p.12).

Como se ha apuntado, Adorno concibe las estéticas negativas o negras como las encargadas de (re)producir lo feo del mundo para denunciarlo, de manera que el arte, bajo su idea, debe ser productor de sensaciones negativas como el desagrado, la pesadumbre o la preocupación. Su teoría estética ha envejecido mal en este aspecto ya que resulta totalitaria en relación a la función que debe desempeñar el arte. Lo mismo sucede con su rechazo total al humor, ya que, como se ha visto, no es ésta una facultad que pertenezca al objeto artístico per se, sino que se trata de una cuestión más compleja: consiste en una correspondencia entre el potencial cómico de lo mostrado -que depende de los condicionantes arriba señalados- y el talento del sujeto para ponerse en dicha disposición frente al objeto artístico.

Al hablar de arte contemporáneo de denuncia social que cuente con cierta repercusión, se puede pensar, por ejemplo, en los documentales de Michael Moore o en las fotografías de Sebastião Salgado. Sin embargo, el primero de ellos, para dar cuenta de las atrocidades cometidas por la administración Bush en Irak no muestra imágenes de poblaciones destruidas o de niños mutilados a causa de los bombardeos, sino que muestra al presidente Bush jugando al golf mientras todo eso sucede fuera de campo. Las fotografías de Salgado, por su parte, sí muestran miseria humana en primera instancia, pero no sin renunciar a un extremo preciosismo gráfico que acaba volviéndose, en ocasiones, perverso. Estas propuestas parecen obedecer a las tesis de Lipovetsky ${ }^{28}$, quien afirma que en las sociedades hedonistas actuales nadie está dispuesto a renunciar a las sensaciones de placer humorístico o estético que buscan las obras de Moore o Sal- 
gado respectivamente. Atendiendo a las aun vigentes teorías de Lipovetsky, un arte contemporáneo dedicado unilateralmente a la denuncia social a la manera defendida por Adorno no parece la forma más eficaz de toma de conciencia en el contexto actual, ya que apenas nadie estaría dispuesto a atenderlo:

El fenómeno humorístico tal como se presenta en nuestros días es inseparable de la edad del consumo. El boom de las necesidades y la cultura hedonista que le acompaña son los que han hecho posibles tanto la expansión humorística como el desclasamiento de las formas ceremoniosas de la comunicación. La sociedad cuyo valor cardinal es la felicidad de masa es arrastrada ineluctablemente a producir y consumir a gran escala signos adaptados a ese nuevo ethos, es decir mensajes alegres, felices, aptos para proporcionar en cualquier momento y para la mayoría una prima de satisfacción directa. (Lipovetsky, 1986, p.156)

Lipovetsky apunta, en los términos empleados en este artículo, que la tendencia del individuo contemporáneo a ponerse en la disposición del juicio humorístico es alta, de manera que no solo el arte, sino que la publicidad también se acoge a dicho precepto. Como señala el pensador francés, en una sociedad resabiada, escéptica y hedonista las formas ceremoniosas de comunicación ya no tienen cabida. Sin embargo, como intuye Quezada-Figueroa, "el humor no resuelve nada, pero puede resultar una incubadora de pensamientos transformadores (...) El humor por sí mismo no lleva contenido un ánimo libertario; sin embargo, su sensación de autonomía y desestructuración nos acerca más a la reflexión" (Quezada-Figueroa, 2015, p.101).

Las teorías que presentan una enmienda a la totalidad en lo que al humor se refiere son, en general, incompletas y caen por su propio peso. Al margen de si éste se activa o no, el sentido del humor frente a cualquier objeto estético amplía y profundiza la mirada. Pone fin a una miopía histórica. Ofrece al ser humano una disposición distinta para reflexionar sobre su propia condición.

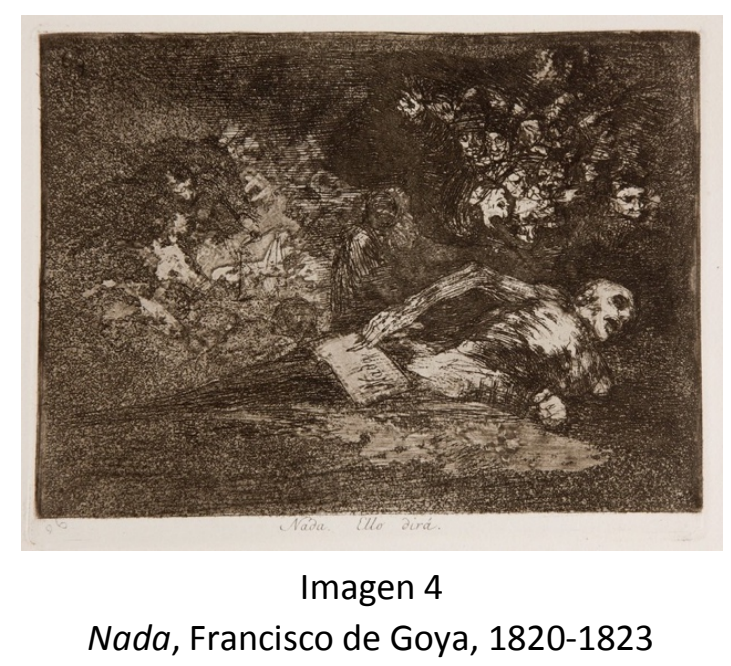


Es por ello que la posibilidad cómica del cuadro de Goya no reside en sus rasgos estéticos, sino precisamente en ignorarlos y extrapolar la experiencia humana que se muestra -en la que puede entenderse que un esqueleto vuelve del infierno informando que no ha encontrado nada allí-a un juicio absoluto sobre el ser humano en general.

\section{BIBLIOGRAFÍA}

ADORNO, T.W.(1971): Teoría Estética. Madrid: Akal.

ARISTÓTELES.(1999): Poética. Barcelona: El Aleph.

BAUDELAIRE, C. (1988): Lo cómico y la caricatura. Madrid: Visor Dis.

BERGSON, H. (1985): La Risa. Ensayo sobre la significación de lo cómico. Madrid: Sarpe.

CAVALLAZZI, A. (2016): Hegel más allá de Hegel: La transgresión cómica de los límites de Hegel en Žižek y Kierkegaard. International journal of Žižek studies, v. 7, n.1.

GÓMEZ HARO, L. (2013): Del humor en el arte contemporáneo: teoría y práctica. Castelló de la Plana: Publicacions de la Universitat Jaume I.

HEGEL, G.W.F.(2003): Lecciones sobre la estética. Madrid: Mestas.

HOBBES, T. (1980): Leviatan. Madrid: Editora Nacional.

KANT, I. (1997): Crítica del juicio. Madrid: Austral/Espasa-Calpe.

KIERKEGAARD, S. (2006): Journals and Papers. Princenton: Princenton University Press.

LIPOVETSKY, G. (1986): La era del vacío: Ensayos sobre el individualismo contemporáneo. Barcelona: Anagrama.

LIPPS, T. (2015): El humor y lo cómico. Mexico: Herder.

ORTEGA Y GASSET, J. (1963): Una primera vista sobre Baroja. Obras Completas. Madrid: Revista de Occidente, vol. II.

QUEZADA-FIGUEROA, A. (2015): Antología estética del humor negro: la risa como toma de conciencia, medio de reflexión y praxis colectiva. Pensamiento: Papeles de filosofía. Nueva época, Año 1, n.2.

TRIAS, E.(2000): Ética y estética. Novenas conferencias Aranguren.

VILAR, G. (2018): Arte y negatividad: releyendo a Adorno. ArtCultura Uberlândia, v. 20, n. 36

WEEMS, I. (2015). Ja! La ciencia de cuándo reímos y por qué.. Barcelona: Penguin Random House, 